\title{
8
}
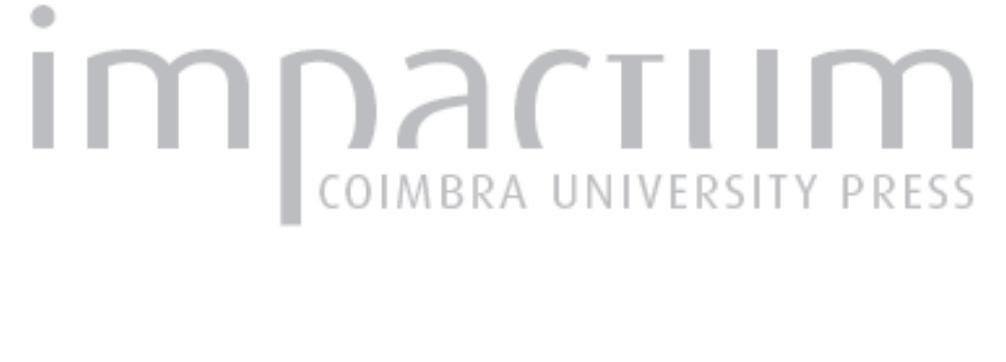

\section{Media e padrões da corrupção política: os casos Freeport e Face oculta}

Autor(es): $\quad$ Cunha, Isabel Ferin

Publicado por: Imprensa da Universidade de Coimbra

URL persistente:

URl:http://hdl.handle.net/10316.2/36963

DOI:

DOI:http://dx.doi.org/10.14195/2183-5462_26_3

Accessed : $\quad$ 26-Apr-2023 13:31:29

A navegação consulta e descarregamento dos títulos inseridos nas Bibliotecas Digitais UC Digitalis, UC Pombalina e UC Impactum, pressupõem a aceitação plena e sem reservas dos Termos e Condições de Uso destas Bibliotecas Digitais, disponíveis em https://digitalis.uc.pt/pt-pt/termos.

Conforme exposto nos referidos Termos e Condições de Uso, o descarregamento de títulos de acesso restrito requer uma licença válida de autorização devendo o utilizador aceder ao(s) documento(s) a partir de um endereço de IP da instituição detentora da supramencionada licença.

Ao utilizador é apenas permitido o descarregamento para uso pessoal, pelo que o emprego do(s) título(s) descarregado(s) para outro fim, designadamente comercial, carece de autorização do respetivo autor ou editor da obra.

Na medida em que todas as obras da UC Digitalis se encontram protegidas pelo Código do Direito de Autor e Direitos Conexos e demais legislação aplicável, toda a cópia, parcial ou total, deste documento, nos casos em que é legalmente admitida, deverá conter ou fazer-se acompanhar por este aviso.

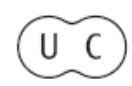




\section{Media Jornalismo}

\section{CORRUPÇÃO POLÍTICA, MEDIA E DEMOCRACIA}




\section{MEDIA E PADRÕES DA CORRUPÇÃO POLÍTICA: OS CASOS \\ FREEPORT E FACE OCULTA \\ MEDIA AND PATTERNS OF POLITICAL CORRUPTION: \\ FREEPORT AND HIDDEN FACE}

\section{ISABEL FERIN CUNHA}

DFCI@FL.UC.PT

\section{Resumo}

Esta comunicação analisa o papel desempenhado pelos media na denúncia da corrupção política, num quadro de profundas mudanças nas sociedades europeias, a partir de 2008, particularmente em Portugal. Neste processo a corrupção política emerge como fenómeno nacional dentro de padrões globalizados (Johnston: 2005), monitorizada por órgãos internacionais de prevenção, bem como por instituições nacionais. Se, por um lado, o jornalismo tem investigado e denunciado procedimentos ilícitos de elites e grupos de interesses, por outro lado, o sistema dos media através de práticas jornalísticas têm normalizado, pela repetição e saturação da visualização, situações e fenómenos excecionais, conferindo às denúncias características de entretenimento popular (Streeck: 2013). Com base nestes enquadramentos teóricos objetivamos caracterizar a corrupção política em Portugal a partir da análise dos canais de televisão de sinal e acesso aberto, RTP1 (canal público), SIC e TVI (canais privados). Para a análise do conteúdo manifesto deste corpus recorremos a um quadro teórico advindo da teoria da corrupção (Johnston: 2005; Economakis, Rizopoulos \& Sergakis: 2010). Os resultados apontam para a prevalência das rotinas na construção da notícia e para a personalização da política nas principais figuras da democracia.

\section{Palavras-chave}

Democracia e Media, Crise Económica Europeia, Corrupção Política, Cobertura Jornalística Televisiva, Análise da Televisão

\section{Abstract}

This paper analyzes the role played by the media in denouncing of political corruption in a context of profound changes in European societies, from 2008, particularly in Portugal. In this process, political corruption emerge as a national phenomenon within globalized standards (Johnston, 2005), monitored by international organizations as well as by national institutions. If, on the one hand, journalism has investigated and denounced illegal procedures by elites and interest groups, on the other hand, the media system through journalistic practices are standardized, by repetition and saturation of visualization exceptional situations and phenomena, giving to the accusations popular entertainment features (Streeck: 2013). Based on these theoretical frameworks we aim 
to characterize the political corruption in Portugal from the analysis of open access television channels, RTP1 (public channel), SIC and TVI (private channels). For the analysis of the manifest content of this corpus we used a theoretical framework arising from the theory of corruption (Johnston: 2005; Economakis, Rizopoulos \& Sergakis: 2010). The results point to the prevalence of the routines in the construction of news and for political personalization on major figures of democracy.

\section{KEYWORDS}

Democracy and Media, European Economic Crisis, Corruption Policy, News Television Coverage, Analysis of Television. 


\title{
MEDIA E PADRÕES DA CORRUPÇÃO POLÍTICA: OS CASOS \\ FREEPORT E FACE OCULTA \\ MEDIA AND PATTERNS OF POLITICAL CORRUPTION: \\ FREEPORT AND HIDDEN FACE
}

\author{
ISABEL FERIN CUNHA | UNIVERSIDADE DE COIMBRA/CIMJ \\ DJCI@UC.FL.PT
}

OS media na Europa num CONTEXTO de mudança

Nas últimas décadas o papel dos media tem vindo a alterar-se na Europa, com o fim ou redução do serviço público, a desregulamentação do setor e as consequentes mudanças na propriedade. Estas transformações implicaram a entrada de capitais que lhe são externos, com culturas diferentes de mercado (por exemplo, no caso de grupos media com origem norte e sul americanos) e de democracia (como os regimes de Angola, China e Rússia). Em simultâneo, tem vindo a efetivar-se a concentração dos grupos media, um pouco por toda a Europa, em corporações com interesses díspares, tais como, a banca, as telecomunicações e outras atividades empresariais. Deste modo, estas empresas e grupos tornaram-se dependentes de recursos e interesses externos à atividade e à cultura da imprensa e do jornalismo, o que tem tido como consequência a diminuição do grau de multipartidarismo e pluralismo nos meios de comunicação e no jornalismo, como constata, em 2012, 0 insuspeitável relatório produzido pelo "The Economist".

A dependência dos media e do jornalismo, quer como atividade económica, quer como atividade profissional, de um campo exterior ao seu, faz com que o financiamento às empresas esteja cada vez mais dependente da informação veiculada como "boa imprensa". 0 que quer dizer que o financiamento tende a depender da "opinião favorável" ou das "omissões convenientes" sobre grupos e interesses empresarias. É a "boa imprensa" que, em última instância, determinará a continuação, o lucro e os postos de trabalho num determinado órgão de comunicação. É o "conformismo" e a repetição do discurso dominante que manterá a publicidade, os sponsors e os patrocinadores de grandes grupos económicos e financeiros, bem como a publicidade institucional do Estado subjugada a organizações financeiras internacionais (Di Tella

10 controlo e os constrangimentos à liberdade de expressão, nos meios mainstream, têm vindo a ser acompanhados pelo desenvolvimento e participação das redes sociais no aprofundamento das democracias. A utilização, pelos cidadãos, de ferramentas como sítios, blogs, facebook e twitter, tornou possível a entrada de novos atores e a diversificação das vozes no espaço público. Os usos institucionais das mesmas ferramentas potencializaram novas formas de participação democrática e de cidadania, ao mesmo tempo que complexificaram as formas de comunicação política e aumentaram a capacidade destes atores veicularem e manipularem informação contingente. A democratização do espaço público, via ferramentas digitais, tem, desta forma, assistido a episódios contraditórios, ora no sentido de aumentar e potencializar a participação cidadã, ora dando origem a guerras de informação e contra-informação no sentido de influenciar eleições e a tomada de decisões políticas. 
e Franceschelli: 2011). A ideia de que a informação e 0 jornalismo, tanto nos media públicos como privados, constituem áreas que devem ser geridas como um qualquer negócio, trouxe como consequência a precarização dos profissionais. Estes, encontram-se cada vez mais atormentados por ameaças de despedimento — na lógica da diminuição de custos salariais, otimização e supressão de funções — 0 que os torna vulneráveis perante as pressões de chefias, gestores, empresas e governantes.

Sistematizando a análise realizada por Streeck (2013:25), podemos avançar para um quadro de atuação dos media, quer públicos quer privados, em que a informação, subjugada ao capitalismo globalizado, viu alterada a ótica de interesse nacional para uma ótica de interesse internacional, onde a conveniência dos sponsors (promotores, anunciantes, etc.) e o princípio do consumo prevalecem face ao de cidadania. Nesta lógica, sobressai o discurso que valoriza direitos contratuais e minimiza os direitos civis e da cidadania, transformando os públicos eleitores em audiências compulsivas. Torna-se, assim, mais importante uma informação que possa garantir ratings e shares, na linha do infoentretenimento, do que a informação aprofundada acerca de eleições e partidos. Esta dinâmica tem como consequência a promoção do star system político vigente, do qual são exemplos os comentadores nas televisões e os partidos políticos do poder. 0 multipartidarismo e as vozes dissonantes ao sistema, tendem, por isso, a ser ignorados.

Apesar de abundar informação, torna-se praticamente impossível aferir a sua qualidade e pertinência, na medida em que a "informação" que realmente interessa e condiciona a vida dos cidadãos não é apresentada ao grande público e circula cada vez mais de forma cifrada, isto é, tecnicamente encriptada e restrita. Exemplo desta situação é o acordo comercial que se encontra em negociação entre a Europa e os Estados Unidos e que virá alterar profundamente o quotidiano europeu, nomeadamente no que respeita aos direitos civis e de consumo. ${ }^{2}$ Segmentam-se assim os públicos e as audiências, confirmando-se a funcionalidade da informação, a qual só se torna acessível a determinadas elites. A situação é tanto mais preocupante quanto se naturaliza a ideia de que em, democracia, a informação e a liberdade de imprensa e de expressão são valores adquiridos, não sendo por isso merecedora de discussão. Na decorrência desta transformação, a lealdade, inerente ao exercício da democracia, é substituída pela confiança nas leis de mercado, celebrada diariamente nos discursos mediáticos da informação.

Quadro 1. Mudanças na atuação nos media na Europa

\begin{tabular}{|l|l|}
\hline $\begin{array}{l}\text { Media atuando no interesse do público } \\
\text { (públicos ou privados) }\end{array}$ & $\begin{array}{l}\text { Media atuando no interesse do capital } \\
\text { (públicos ou privados) }\end{array}$ \\
\hline Nacional & Internacional \\
\hline Cidadãos & Sponsers/consumidores \\
\hline Direitos civis & Direitos contratuais \\
\hline Eleitores & Audiências \\
\hline Eleições periódicas & Ratings e sharings contínuos \\
\hline
\end{tabular}

2 Cfr. The Transatlantic Trade Investement Partnership (TTIP). http://ec.europa.eu/trade/policy/ in-focus/ttip/ 


\begin{tabular}{|l|l|}
\hline Multipartidarismo & Partidos do poder \\
\hline Opinião pública & Indicadores seletivos de audiências \\
\hline Liberdade de expressão & Liberdade de mercado \\
\hline Valor: Lealdade & Valor: Confiança \\
\hline Serviços de interesse público & Serviços de interesse de mercado \\
\hline
\end{tabular}

Fonte: Elaboração de Isabel Ferin Cunha a partir de Streeck, W. (2013: 25)

0 Quadro 1 resume e compara as mudanças operadas na atuação dos media, públicos e privados, na Europa, a partir do novo milénio mas, principalmente, na última década. Na comparação sobressaem os valores que promovem a dimensão de mercado e da democracia formal da atividade dos media, em prejuízo do serviço do interesse público e da democracia social. Observamos o desvanecimento do tradicional papel dos media como garantes de cidadania e da liberdade de expressão, bem como a conceção das audiências como públicos e cidadãos. Em contrapartida, ganham protagonismo as audiências consumidoras de serviços oferecidos por anunciantes, promotores e sponsers. Neste cenário, os media nacionais do Sul da Europa — principalmente nas televisões de sinal aberto, como em Portugal — têm tido um papel muito relevante na promoção de valores que visam apoiar a iniciativa privada e o mercado, o que por si só seria louvável. No entanto, surgem também associados à desclassificação das actividades fundamentais da democracia social, tais como a educação e a saúde. Os discursos dos media informativos, mas não só, tendem a generalizar e a classificar todo o setor público como ineficiente e corrupto - para o que contribui a denúncia de inúmeros casos de corrupção política — ao mesmo tempo que exaltam as virtudes dos setores empresarias e financeiros, ignorando as suas actividades corruptoras ${ }^{3}$ e as suas reivindicações neoliberais cada vez mais extremadas.

\section{PADRÕES DA CORRUPÇÃO}

A corrupção carateriza-se por constituir um abuso de poder em benefício próprio de agentes políticos democraticamente eleitos, situação que pode ocorrer durante ou após o exercício de funções públicas. Segundo Blankenburg (2002), estas situações tendem a agudizar-se em momentos de crise económica, financeira e política, quando os recursos disponíveis escasseiam e se dá, por motivos vários, processos de descredibilização e de deterioração das instituições públicas e privadas.

Numa análise "generalizante" da corrupção política nos países do Sul da Europa, identificamos alguns fatores comuns que podem justificar o surgimento daqueles fenómenos. Entre eles assinalamos os processos de democratização recente, após décadas de ditadura; a emergência de novas elites políticas e económicas, portadoras de novas conceções de ética pública; e a tendência crescente de profissionalização dentro dos partidos. Neste último aspeto observamos que os candidatos a cargos de governação advêm preferencialmente das "escolas de partidos", circunstância que tende a estimular lealdades entre grupos etários, dentro e entre partidos, em detrimento da responsabilidade perante os cidadãos. Relevantes são,

3 Cfr OCDE (2014) Foreign Bribery Report: An Analysis of the Crime of Bribery of Foreign Public Officials http://www.oecd.org/corruption/oecd-foreign-bribery-report-9789264226616-en.htm 
ainda, fenómenos como a chegada dos fundos estruturais europeus, uma injecção de biliões de euros nos orçamentos desses países durante as décadas de oitenta e noventa, e o funcionamento arcaico da justiça, dotada de legislação e métodos de investigação inadequados a uma nova tipologia de crime globalizado. Acompanha, ainda, este processo, a expansão e a entrada das classes médias na sociedade de consumo, bem como o fim dos monopólios dos media de serviço público e a consequente liberalização deste mercado.

Neste contexto, de crescente mercantilização da política e da sociedade, os ilícitos tendem a ocorrer quando os agentes políticos se defrontam com a oportunidade e os meios instrumentais e racionais de efetivação do crime, assim como com a pressão da necessidade coletiva (como o financiamento de partidos) ou individual (por exemplo, dívidas ou ambições de consumo). Identificam-se quatro situações-tipo em que normalmente se concretizam os crimes de corrupção: 1) quando os agentes ou ex-agentes políticos competem por cargos políticos; 2) quando os mesmos exercem cargos públicos; 3) quando aqueles legislam e governam. A quarta situação, em crescimento em todos os países do Sul da Europa, dá-se após o abandono de cargos de governação, quando os agentes políticos mantêm o seu capital relacional acumulado naquelas funções públicas, as quais, posteriormente, colocam ao serviço de funções privadas, no campo da economia, finanças ou banca, para benefício próprio ou do seu grupo.

Na perspetiva de Blankenburg (2002), bem como de Johnston (2005), a corrupção política está diretamente vinculada à cultura nacional e, muito particularmente, a como as elites se relacionam com a res publica. Determinantes do grau e caraterísticas da corrupção política, em cada país ou região, são as pressões económicas e políticas de interesses internacionais, anónimos e deslocalizados, tais como "investidores", "fundos" e multinacionais. Deste modo, não se poderá conceber uma escala única de corrupção política aplicável a todos os países, pois cada um terá a sua especificidade cultural e diferente capacidade de resistência a solicitações económicas e financeiras organizadas. Outros fatores deverão, ainda, ser tomados em conta: o grau de aprofundamento da democracia, o funcionamento das instituições políticas e sociais e a capacidade e disponibilidade de participação e mobilização dos cidadãos. As caraterísticas da corrupção política dependem, segundo a perspetiva liberal destes autores, do nível de abertura dos mercados à competitividade e de mecanismos de regulação da concorrência. Num cenário de transição para uma economia aberta e globalizada, são apontados como momentos "críticos" para o crescimento da corrupção política, as privatizações de empresas públicas, as concessões de serviços a privados, sobretudo no âmbito da energia e telecomunicações, assim como as designadas parcerias público-privadas (PPP) para a construção de infra-estruturas.

Os ilícitos mais frequentes são os crimes contra o Estado, os crimes contra 0 Estado cometidos no exercício da função pública, a corrupção ativa e passiva (para ato ilícito ou lícito), o peculato (que inclui peculato de uso e por erro de outrem), a participação económica em negócio, a concussão, o abuso de poder, o tráfico de influências, o branqueamento de capitais e a violação de regras urbanísticas. Por conseguinte, há muitos tipos de corrupção que variam em função do setor em que ocorrem (público ou privado; político ou administrativo) e dos atores que envolvem (por exemplo, funcionários públicos, políticos, empresários ou gestores). Para a aná- 
lise daqueles fenómenos é necessário, igualmente, ter em conta o grau e índice de impacto (local, nacional ou transnacional), para além do nível de formalização e organização das redes, podendo estas ser ocasionais e esporádicos ou estruturais e sistemáticas.

Considerando que num mundo globalizado a corrupção política ocorre em países com diversas formas de economia e governação — mas que a caminhada de todos os países visa a "liberalização" — Johnston (2005) identificou quatro "síndromes de corrupção". Estes padrões da corrupção correspondem, segundo ele, a quatro formas de combinar a política e a economia, tendo em consideração a qualidade das suas instituições públicas, económicas e financeiras.

No Quadro 2 sistematizamos as quatro síndromes propostas por Jonhston (2005) e as suas principais caraterísticas políticas, sociais, económicas e institucionais.

Quadro 2. Síndromes da Corrupção

\begin{tabular}{|l|l|l|l|l|}
\hline \multirow{2}{*}{$\begin{array}{l}\text { Tipo de } \\
\text { Síndrome }\end{array}$} & $\begin{array}{l}\text { Grau de Participação } \\
\text { dos cidadãos }\end{array}$ & $\begin{array}{l}\text { Grau de Participação } \\
\text { dos cidadãos }\end{array}$ & $\begin{array}{l}\text { Qualidade das } \\
\text { Instituições }\end{array}$ & $\begin{array}{l}\text { Qualidade das } \\
\text { Instituições }\end{array}$ \\
\cline { 2 - 5 } & Oportunidades Políticas & $\begin{array}{l}\text { Oportunidades } \\
\text { Económicas }\end{array}$ & $\begin{array}{l}\text { Estado/ } \\
\text { Sociedade }\end{array}$ & $\begin{array}{l}\text { Instituições } \\
\text { Económicas }\end{array}$ \\
\hline $\begin{array}{l}\text { Influência dos } \\
\text { Mercados } \\
\text { (Influence } \\
\text { Market) }\end{array}$ & $\begin{array}{l}\text { Democracias maduras } \\
\text { (democracia participativa; } \\
\text { competição constante e } \\
\text { debate entre tendências) }\end{array}$ & $\begin{array}{l}\text { Mercados maduros } \\
\text { (liberalizados; abertos; } \\
\text { regulados/mto competi- } \\
\text { tivos; índices altos de } \\
\text { bem-estar) }\end{array}$ & Ampla/Extensa & Forte \\
\hline $\begin{array}{l}\text { Cartéis de } \\
\text { Elites } \\
\text { (Elite Cartel) }\end{array}$ & $\begin{array}{l}\text { Democracias em fase } \\
\text { consolidação/reforma } \\
\text { (democracia com crescente } \\
\text { participação e competição) }\end{array}$ & $\begin{array}{l}\text { Mercados em fase } \\
\text { de reforma (abertos e } \\
\text { liberalizados em grande } \\
\text { parte; regulação em } \\
\text { aprendizagem; crescente } \\
\text { competição; índices de } \\
\text { bem-estar médios) }\end{array}$ & Moderada & Média \\
\hline $\begin{array}{l}\text { Oligarcas e } \\
\text { Clãs } \\
\text { (Oligarch and } \\
\text { Clan) }\end{array}$ & $\begin{array}{l}\text { Regimes de transição } \\
\text { (democracias recentes; } \\
\text { competição significativa } \\
\text { mas pouco estruturada) }\end{array}$ & $\begin{array}{l}\text { Mercados Novos } \\
\text { (liberalização recente; } \\
\text { não regulados; grande } \\
\text { desigualdade e pobreza) }\end{array}$ & Fraca & Fraca \\
\hline $\begin{array}{l}\text { Funcionários } \\
\text { e Magnatas } \\
\text { (Official Moguls) }\end{array}$ & $\begin{array}{l}\text { Não é uma democra- } \\
\text { cia (escassa abertura e } \\
\text { participação condicionada } \\
\text { a grupos, partidos, etc.) }\end{array}$ & $\begin{array}{l}\text { Mercados em con- } \\
\text { strução } \\
\text { (liberalização recente; } \\
\text { não regulados; enorme } \\
\text { desigualdade e pobreza) }\end{array}$ & Fraca & Fraca \\
\hline
\end{tabular}

Fonte: Elaboração de Isabel Ferin Cunha a partir de Johnston (2005: 40)

\section{Perceção e cobertura jornalística da CORRUPÇÃo na teleVisão}

Como se sabe, a perceção advém da formação de impressões, tem um caráter inferencial e determina uma forma de conhecer hipotética que advém da agregação de informação disponível (Vala e Monteiro: 1996).

É atribuído aos meios de comunicação, principalmente à televisão, a construção da perceção sobre a corrupção política, crime cuja natureza implica necessariamente 0 segredo e a ocultação. A perceção deste ilícito pela opinião pública depende 
da cobertura jornalística mas esta está, como anteriormente referimos, diretamente vinculada à liberdade de imprensa e de expressão, bem como a outras variáveis como a independência dos media face ao poder político e económico (Roca, Alidedeoglu-Buchner: 2010). Contudo, a perceção do público é uma construção individual que depende de fatores como a credibilidade, a confiança e a responsabilidade atribuídas, ou depositadas, em instituições e agentes.

No caso da cobertura jornalística da corrupção política, assiste-se a uma tensão entre a perceção - constituída pelos fatores de credibilidade, confiança e responsabilidade - de cada cidadão sobre cada um dos meios de comunicação, e a perceção - constituída pelos fatores de credibilidade, confiança e responsabilidade - de cada cidadão sobre a democracia e a atuação dos políticos. No amago desta tensão —onde deverão ser equacionados fatores inerentes ao estatuto económico, social, etário e profissional de cada cidadão - emerge a perceção sobre os fenómenos de corrupção política.

Estes elementos condicionam a leitura dos índices de corrupção divulgados pelos relatórios internacionais, o que não impede que se constate que a perceção deste fenómeno esteja, na generalidade, em crescimento junto da opinião pública dos países do Sul da Europa, designadamente em Portugal. Por outro lado, a corrupção política tem sido um dos fenómenos com maior cobertura nos meios de comunicação noticiosos desde o início da crise, em 2008. Os meios de comunicação têm tido o papel de denúncia e de desocultação que, para muitos autores, constituem matéria-prima de uma "indústria de escândalos" (Schudson: 2004), uma vez que os acontecimentos noticiados agregam alto valor noticioso pelas "ruturas" nas expectativas que proporcionam na opinião pública. Os relatórios periódicos sobre a corrupção, divulgados pelas organizações internacionais, identificam também os meios de comunicação, principalmente a televisão, como fontes privilegiadas para a perceção da corrupção.

Salientamos que a partir do início do milénio, num quadro de crescente crise económica em Portugal, acentuou-se a visibilidade das denúncias de corrupção política nos media. A justificação para este fenómeno deve-se ao fluxo de verbas provenientes da União Europeia no âmbito dos Fundos Estruturais, aplicados sem a adequada fiscalização (Morgado e Vegar: 2003). Ao mesmo tempo, acentua-se a " perceção de impunidade" que parece envolver os "crimes de colarinho branco", dada a incapacidade do sistema penal se modernizar no combate a este novo tipo de criminalidade. Para o aumento da perceção negativa junto da opinião pública tem contribuído a discrepância entre o número de casos de corrupção divulgados pela imprensa e os processos julgados, aumentando a perceção de impunidade. As estatísticas divulgadas confirmam, ainda, que o número de arguidos acusados difere largamente do número de arguidos condenados (Maia: 2008), facto que acentua, aos olhos da opinião pública, a diferença entre "as condenações" e a visibilidade mediática atribuída aos casos.

Ressaltamos que a liberalização do mercado mediático em Portugal se deu no final da década de oitenta, início da década de noventa, com a abertura do mercado a operadores privados de televisão — até então só existia a RTP1 e a RTP2 ${ }^{4}$,

4 Estes dois canais públicos integram o grupo Rádio e Televisão de Portugal: http://www.rtp.pt/ 
canais públicos - e o surgimento da SIC $(1992)^{5}$ e da TVI (1993). ${ }^{6}$ Observamos que dois destes canais (SIC e TVI) fazem parte de grupos com participação de capital não português, angolano no caso da SIC, por meio da Newshold, e capital espanhol e latino-americano na TVI, maioritariamente detida pelo Grupo Prisa. ${ }^{7}$ Notamos ainda que nos últimos anos (2011-2015) o financiamento governamental ao sector público da comunicação foi por diversas vezes posto em causa e aventada a questão da privatização. A crise de 2011 acentuou as dificuldades do sector público, mas também privado, dada a contração e redistribuição da publicidade, entre canais abertos e pagos, e a migração dos grandes anunciantes para a internet.

0 contexto esboçado anteriormente constitui o quadro de referência para a análise da mediatização de dois casos de corrupção política nas televisões de sinal aberto (RTP1, SIC e TVI): os casos Freeport e Face Oculta (Anexo I). A escolha destes casos fundamenta-se em algumas das suas características comuns, tais como o facto de ambos envolverem o Primeiro-Ministro do Partido Socialista, José Sócrates, que se manteve em funções dois mandatos, de 2005 a 2009 e de 2009 a maio de 2011, mês em que Portugal solicitou a intervenção das instituições de resgate, Fundo Monetário Internacional (FMI), Banco Central Europeu (BCE) e União Europeia (UE). Outras características são igualmente relevantes nestes dois casos, a saber, o envolvimento de ex-ministros, de empresas internacionais, de empresas públicas nacionais e seus administradores, assim como a movimentação de capitais para paraísos fiscais.

\section{Cobertura jornalística teleVisiva da CORRupção: METODOLOGIA, INDICADORES E INTERPRETAÇÃO}

Após a anterior contextualização dos media e da televisão, debruçamo-nos sobre a cobertura jornalística. Recorremos aos métodos mistos, qualitativos e quantitativos, não só na análise de conteúdo mas, posteriormente, na interpretação dos indicadores recolhidos. 0 corpus foi constituído por jornais noticiosos do prime-time dos três canais RTP1 (público) SIC e TVI (privados) sobre os dois casos citados, num total de 1609 notícias (designadas, no texto, peças), recolhidas de 2005 a 2012 pela empresa Marktest/Mediamonitor. Dado 0 volume deste corpus e em função dos casos terem início em anos diferentes - o caso Freeport em 2005 e o caso Face Oculta em 2009 — optámos por nos centrar em 2009, ano que regista mais notícias (1045 peças). Este ano é particularmente importante na medida em que é reeleito o Primeiro-ministro em exercício, o socialista José Sócrates, que até ao início da campanha eleitoral — início de setembro de 2009 - obteve grande visibilidade em notícias associadas aos casos Freeport e Face Oculta, como demonstra o Quadro 3.

5 Sociedade Independente de Comunicação (SIC): http://sic.sapo.pt/

6 Televisão Independente (TVI): www.tvi.iol.pt

7 Cfr: Figueiras, R (2014). 0 Sistema dos media em Portugal no contexto da globalização do século XXI In: Cunha, I. F. \& Serrano, E. (coords.). Cobertura Jornalística da Corrupção Política (pp. 253281). Lisboa: Alêtheia. 
Quadro 3. Visibilidade (número de peças/ano 2009) dos Casos Freeporte Face Oculta nos três canais abertos

\begin{tabular}{llllllllll}
\hline Casos & \multicolumn{2}{l}{ Freeport } & \multicolumn{4}{c}{ Face Oculta } & \multicolumn{3}{c}{$\begin{array}{c}\text { Total } \\
\text { Geral }\end{array}$} \\
\hline Canais & RTP1 & SIC & TVI & Total & RTP1 & SIC & TVI & Total & \\
\hline $2009 / N^{0}$ Notícias & 195 & 259 & 235 & $\mathbf{6 8 9}$ & 123 & 128 & 105 & $\mathbf{3 5 6}$ & $\mathbf{1 0 4 5}$ \\
\hline
\end{tabular}

Fonte: Dados da empresa Marktest/Mediamonitor (registo desenvolvido pela equipa do Projeto “Corrupção Política nos media: uma perspetiva comparada")

A análise do conteúdo manifesto dos noticiários deu origem a duas bases de dados em SPSS (Freeporte Face Oculta), cada uma constituída por 32 variáveis, onde a peça noticiosa de cada um dos jornais televisivos, independentemente do género jornalístico, foi considerada a unidade de análise. ${ }^{8}$ Considerámos 0 universo de análise 0 conjunto das peças dos jornais televisivos que abordaram a corrupção política e foram disponibilizadas na plataforma e-telenews da empresa Marktest/Mediamonitor. A construção das bases de dados envolveu a organização de um codebook com as definições das variáveis e modalidades, a realização de pré-testes e a validação das duas bases constituídas. Os dados que iremos apresentar referem-se à totalidade das peças dos casos Freeporte Face Oculta exibidas no ano de 2009 nos canais de sinal aberto. Não foram considerados os espaços televisivos dos comentadores nos noticiários.

Tendo em consideração a tipologia de síndromes da corrupção de Johnston (2005), apresentadas no Quadro 2, procurámos, a partir dos indicadores das bases de dados dos dois casos analisados, observar alguns fatores referentes à Caraterização Política (Gráfico 1 e 2) ${ }^{9}$ e à Qualidade das Instituições (Gráficos 3, 4, 5 e 6) ${ }^{10}$, tal como são apresentados, respectivamente, nos padrões "Influência dos Mercados" e "Cartéis de Elites" apresentados nos Quadros 2 e 4 . Com esta análise, pretendemos compreender, à luz do autor citado, se há elementos na cobertura jornalística televisiva portuguesa que permitam indiciar o tipo, ou os tipos, de síndrome de corrupção descritos por aquele autor e identificados em outras circunstâncias por outros pesquisadores (Morgado e Vegar: 2003; Sampaio: 2013; 2014) na sociedade portuguesa.

Quadro 4. Caraterísticas das Síndromes de Corrupção e indicadores de análise

\begin{tabular}{|c|c|c|c|c|}
\hline $\begin{array}{l}\text { Tipo de } \\
\text { Síndrome }\end{array}$ & $\begin{array}{l}\text { Caraterização } \\
\text { Política }\end{array}$ & $\begin{array}{l}\text { Caraterização } \\
\text { Económica }\end{array}$ & $\begin{array}{l}\text { Qualidade das } \\
\text { Instituições Públicas }\end{array}$ & $\begin{array}{l}\text { Qualidade das Insti- } \\
\text { tuições Económicas e } \\
\text { Financeiras }\end{array}$ \\
\hline $\begin{array}{l}\text { Indicadores } \\
\text { de análise }\end{array}$ & $\begin{array}{l}\text { Indicadores de } \\
\text { análise temática/ln- } \\
\text { dicadores de análise } \\
\text { de atores /Tom }\end{array}$ & $\begin{array}{l}\text { Indicadores de } \\
\text { análise temática } \\
\text { /indicadores de } \\
\text { atores Institu- } \\
\text { ições/Tom }\end{array}$ & $\begin{array}{l}\text { Indicadores de análise } \\
\text { de atores/ Papeis dos } \\
\text { atores/Tom/Indicadores } \\
\text { de análise de ilícitos }\end{array}$ & $\begin{array}{l}\text { Indicadores de análise } \\
\text { de atores/ papéis dos } \\
\text { atores/Tom/Indicadores } \\
\text { de análise de ilícitos }\end{array}$ \\
\hline
\end{tabular}

Fonte: Elaboração de Isabel Ferin Cunha a partir de Johnston (2005: 40)

8 A base de dados foi desenvolvida pela bolseira do projeto, Mestre Patrícia Contreiras Manso.

9 Anexo l, final do artigo, p. 60.

10 Anexo l, final do artigo, p. 60. 
Em busca dos indicadores referidos, empreendemos três exercícios apoiados nos outputs retirados das bases em SPSS. 0 primeiro exercício cruza as variáveis ator (os dez atores mais citados) e tema (os dez temas principais) (Gráfico 1 e 2) ${ }^{11}$. 0 segundo exercício incide sobre as Instituições Públicas (as 10 instituições mais nomeadas) e os llícitos (os 10 mais nomeados) que lhe estão associados (Gráfico 3 e 4)12. 0 terceiro e último exercício coteja as Instituições Privadas (as instituições mais nomeadas) e os llícitos (os 10 mais nomeados) (Gráfico5 e 6) $)^{13}$.

No primeiro exercício, observamos que no caso Freeport, num total de 689 peças, os dez principais atores identificados, por ordem de referências, são: José Sócrates (136 peças, 19,7\%), Lopes da Mota (63 peças, 9,1\%), Pinto Monteiro (53 peças, 7,7\%), Charles Smith (44 peças, 6,4\%), Júlio Monteiro (30 peças, 4,4\%), Cândida Almeida (28 peças, $4,1 \%$ ), Cavaco Silva (17 peças, 2,5\%), Alberto Costa (16 peças, 2,3\%), Carlos Guerra (16 peças, 2,3\%) e Manuel Pedro (16 peças, 2,3\%).

0 tema com maior incidência é "declarações" (186 peças), onde o Primeiro-ministro (PM) surge em 48 peças $(38,7 \%)$, seguido pela Procuradora Cândida Almeida (14 peças, 11,3\%). 0 PM surge ainda com visibilidade no tema "investigações/ buscas, interrogatórios/ inquirições do Ministério Público e da Polícia Judiciária" (no total 70 peças) — onde, junto com Charles Smith, recolhe, respectivamente, 11 peças $(28,2 \%)$ e 16 peças (correspondente a $41 \%$ ). 0 PM surge, ainda, associado 1) ao tema "licenciamento do Freeport" (num total de 40 peças, 11, 55\%); 2) a "comunicados" (num total de 29 peças, 8, 34,8\%); 3) a "investigações no Reino Unido" (em 21 peças, 11, 68,8\%) e no "caso DVD" (em 15 peças, 6, 60\%). Lopes da Mota, 0 segundo ator mais nomeado está associado 1) ao "caso Eurojust" (num total de 55 peças, apresenta 36, 78,3\%) e 2) a "pressões sobre a Justiça" (num total de 39 peças, é referido em 14,56\%). 0 terceiro ator, Pinto Monteiro, regista 21 peças $(16,9 \%)$ no tema "declarações" e 5 peças $(21,7 \%)$ em "comunicados".

A exposição qualitativa dos dados apurados no caso Freeport demonstra que 0 protagonista é, sem dúvida, o Primeiro-ministro José Sócrates. Aquela descrição confirma, ainda, que este está preferencialmente associado a "declarações" proferidas no âmbito das investigações realizadas em Inglaterra, que deram origem à divulgação de um DVD com acusações de suborno do principal arguido (o empresário Charles Smith) ao Primeiro-ministro, bem como "declarações" proferidas a propósito do designado caso Eurojust ${ }^{14}$. 0 Primeiro-ministro é ainda implicado em irregularidades no licenciamento do outletFreeport, enquanto Secretário de Estado do Ambiente. A cobertura jornalística estabeleceu relações de proximidade entre 0 então Primeiro-ministro e o presidente (desde 2007) do Eurojust, o procurador-geral adjunto Lopes da Mota, acusado de "travar" os desdobramentos do processo Freeport em Inglaterra e de exercer pressões sobre os procuradores encarregados do processo em Portugal. Para além de atores do Ministério Público — como o Procu-

11 Anexo l, final do artigo, p. 60.

12 Anexo l, final do artigo, p. 60.

13 Anexo I, final do artigo, p. 60.

14 Cfr: Eurojust é um organismo da União Europeia que congrega informações e trabalho do Ministério Público de todos os países europeus com vista a lutar contra a criminalidade organizada e transfronteiras. Está sedeada em Haia na Holanda www.eurojust.europa.eu/ 
rador-Geral da República, Pinto Monteiro, e a Procuradora Geral Adjunta, Cândida Almeida — adquiriram protagonismo 0 intermediário dos "indiciados " como corruptores (não foi provado em julgamento), o inglês Charles Smith e os familiares do Primeiro-ministro (o tio Júlio Monteiro, outros tios e primos), suspeitos de funcionarem como "possíveis" "testas de ferro" para a recetação de "luvas"(não foi provado).

No caso Face Oculta o cruzamento das variáveis relativas aos atores e temas principais (Gráfico 2) ${ }^{15}$ regista 342 peças, sendo que Armando Vara e o Primeiro-ministro José Sócrates, os principais protagonistas citados, recolhem respetivamente $69(20,2 \%)$ e 44 peças (12,9\%). Armando Vara está associado 1) a "investigações/ buscas/interrogatórios e inquirições (24 peças, 50\%); 2) à "suspensão de funções" (16 peças, 80\%) e 3) a "constituição de arguidos" (7 peças, 64\%). 0 PM é nomeado a respeito de 1) "escutas" (30 peças, 68\%); 2) "declarações" (7 peças, 30\%) e 3)"partidos políticos" (3 peças, 60\%).

Numa perspetiva interpretativa, observamos que, neste caso, o principal ator, o ex-ministro e deputado Armando Vara, amigo do Primeiro-ministro, José Sócrates, é quem regista maior visibilidade. Ele é associado às diligências do Ministério Público no âmbito de ações de rotina, tais como investigações, buscas, interrogatórios e inquirições. A questão da sua suspensão de funções no Banco Comercial Português (BCP), onde exercia um alto cargo de gestão após ter transitado da CGD a convite do então presidente, o banqueiro socialista Santos Ferreira, também obtém grande proeminência. Sublinhamos que o Primeiro-ministro surge como o segundo ator com maior visibilidade, associado ao episódio das "escutas" telefónicas, realizadas pela polícia de investigação. Estas "escutas", que estabelecem uma relação de proximidade entre $0 \mathrm{PM} \mathrm{e} 0$ arguido Armando Vara, deram origem à abertura de um novo processo sobre a interferência do Primeiro-ministro na possível compra de um canal privado de televisão (TVI) pela Portugal Telecom (PT). Segundo a cobertura jornalística, as "escutas" permitiam "estabelecer ligações" pouco claras, entre o ex-membro do governo e o Primeiro-ministro, o que não deixa de ser alvo de questionamento pelos partidos políticos da oposição, designadamente nos debates quinzenais na Assembleia da República. Ressaltamos ainda que o corruptor, Manuel Godinho, um empresário desconhecido da área da reciclagem de resíduos e metais, surge como terceiro ator mais nomeado, associado às investigações e buscas, assim como às medidas de coação e à acusação de corrupção.

A informação sobre a substância de cada um dos casos de corrupção vem normalmente em plano secundário — como, no caso Freeport, o licenciamento da construção em área de natureza protegida, ou, no caso Face Oculta, os crimes económicos contra 0 Estado e 0 tráfico de influências - e a partir das acusações realizadas pela justiça ao longo das diferentes fases do processo. No entanto, existem determinados temas colaterais que criam perceções públicas sobre a fragilidade da Justiça, tais como "pressões sobre a justiça", a "violação do segredo da justiça" ou incertezas acerca da legitimidade de "escutas" realizadas por organismos da Polícia e do sistema judiciário. Por fim, observamos que tanto no caso Freeport como no caso Face Oculta, o Presidente da República surge, também, entre os principais atores, associado a "declarações" onde geralmente recusa prenunciar-se sobre os casos.

15 Anexo l, final do artigo, p. 60. 
0 segundo exercício incide sobre as Instituições Públicas (as 10 instituições mais nomeadas) e os llícitos (os 10 mais nomeados) que the estão associados (Gráfico 3 e 4). ${ }^{16}$ Os outputs relativos à intersecção entre Instituições Públicas e llícitos mostram que no caso Freeport (689 peças), mais de $80 \%$ das peças que registam instituições públicas, não assinalam ilícitos (Gráfico 3) ${ }^{17}$. No caso Freeportas instituições públicas com maior visibilidade são o Ministério Público (257 peças, 14,6\%), as Autoridades Portuguesas (146 peças, 8,3\%), as Autoridades Britânicas (120 peças, 6,8\%), o Ministério do Ambiente (MA) (110 peças, 6,3\%), o Eurojust (92 peças, 5,2\%), as Câmaras Municipais (66 peças, 3,8\%), o Sindicato dos Magistrados do Ministério Público (SMMP) (46 peças, 2,6\%), a Assembleia da República (AR) (34 peças, 1,9\%), os Tribunais (18 peças, 1\%) e os Serviços de Informação e Segurança (SIS) (13 peças, 0,7\%).

Relativamente ao Ministério Público, 256 peças (99,6\%) não referem qualquer ilícito, sendo que existem 146 peças $(24,1 \%)$ associadas a "corrupção" e 33 peças (12,8\%) a "suborno". As Autoridades Portuguesas estão igualmente relacionadas com os crimes de "suborno" em 39 peças (26,7\%), sendo que existem 146 peças em que que não é referido qualquer tipo de ilícito. Associado às Autoridades Britânicas, existem 43 peças (35,8\%) sobre "corrupção" e 42 peças (35\%) sobre "suborno", sendo que não há menção a nenhum ilícito em 118 (98,3\%) peças. Relacionado ao Ministério do Ambiente (MA), existem $108(98,2 \%)$ peças sem referência a ilícitos. Também o MA está associado a crimes de "corrupção" (num total de 36 peças, 32,7\%) e a "suborno" (32 peças, 29,1\%).

No caso Face Oculta (342 peças) observamos, que 62,9\% das peças não assinalam ilícitos (Gráfico 4) ${ }^{18}$. Neste caso as instituições com mais visibilidade são 0 Ministério Público (161 peças, 18,6\%), a Rede Eléctrica Nacional (REN) (62 peças, 7,2\%), o Tribunal de Aveiro/DIAP (40 peças, 4,6\%), a Polícia Judiciária (PJ) (31 peças, 3,6\%), a Rede Ferroviária Nacional (REFER) (30 peças, 3,5\%), a Energias de Portugal (EDP) (25 peças, 2,9\%), a Gás e Petróleo de Portugal (GALP) (16 peças, 1,8\%), a Portugal Telecom (PT) (14 peças, 1,6\%), o Banco de Portugal (BdP) (13 peças, 1,5\%) e a Banco Português de Negócios (BPN) (7 peças, 0,8\%).

Associado ao Ministério Público encontramos 160 peças (65,6\%) que não referem qualquer ilícito, sendo que existem 29 peças $(11,9 \%)$ que correspondem ao ilícito "tráfico de influências" e 25 peças $(10,2)$ relativas ao crime de "corrupção". Sobre a REN observamos que não há menção a nenhum ilícito em 59 peças (50\%), sendo que constatamos que a empresa está relacionada com o ilícito "tráfico de influências" em 24 peças (20,3\%), seguido do crime "corrupção" com 21 peças (17,8\%). Também registamos que o Tribunal de Aveiro/DIAP está associado ao crime "tráfico de influências" (em 15 peças, 20\%) e ao crime de "corrupção" (11 peças, 14,7\%). A PJ, a EDP e a GALP estão igualmente vinculadas à nomeação dos crimes de "tráfico de influências", repetivamente, 10 peças, $16,9 \%$, 11 peças $22 \%$ e 6 peças, $17,6 \%$. A REFER está relacionada ao crime de "corrupção"(9 peças, 16,/\%) e de "tráfico de influências"(7 peças, 13\%).

$\mathrm{Na}$ busca da qualidade atribuída pela cobertura jornalística às instituições públicas, observamos que a maior parte não têm ilícitos associados (Gráfio 3 e 4). ${ }^{19}$

16 Anexo I, final do artigo, p. 60.

17 Anexo I, final do artigo, p. 60.

18 Anexo I, final do artigo, p. 60.

19 Anexo I, final do artigo, p. 60. 
No entanto, paira sobre as direções das empresas públicas com participação do Estado em 2009 - a REN, a REFER, a EDP ou a GALP, as quais, envolvidas no caso Face Oculta eram, nesse ano, empresas com participação do Estado - e sobre os seus gestores, com filiações a partidos políticos do centro democrático, não só insinuações de crimes contra o Estado, como também de má gestão e tráfico de influências. Em ambos os casos de corrupção analisados, a instituição pública com maior proeminência é o Ministério Público que, pela sua natureza, é a promotora das investigações de ilícitos. As autoridades portuguesas e inglesas nomeadas no caso Freeport estão igualmente relacionadas com a investigação de crimes. Na nomeação destas instituições observamos que o Ministério Público e as instituições portuguesas surgem discursivamente conotadas com procedimentos temporais lentos e prolongados, enquanto as autoridades inglesas, no mesmo caso Freeport, e apesar do arquivamento em Inglaterra do processo investigado, surgem caraterizadas como eficientes e expeditas, criando a perceção de uma justiça eficaz e de resultados.

0 terceiro e último exercício tem como objetivo cotejar as Instituições Privadas (as instituições mais nomeadas) e os llícitos (os 10 mais nomeados) (Gráfico5 e 6). ${ }^{20}$ No caso Freeport (689 peças) (Gráfico 5) ${ }^{21}$ as instituições privadas mais nomeadas são Empresa Smith \& Pedro (82 peças, 4,7\%), Empresas Internacionais (33 peças, 1,9\%), Escritório de Advogados Vasco Vieira de Almeida \& Associados (13 peças, $0,7 \%$ ); Escritórios de Advogados de José Francisco Gandarez \& Associados (12 peças, 0,7\%); Quercus (11 peças, 0,6\%); Empresa ISA- Investimentos Imobiliários, LDA (10 peças, 0,6\%); Bancos (10 peças, 0,6\%); Empresa Neurónio Criativo Publicidade e Marketing (9 peças, 0,5\%); Ateliê Arquitecto Eduardo Capinha Lopes, Lisboa (8 peças, 0,5\%) e Associação Cívica «Força Emergente» (4 peças, 0,2\%).

$\mathrm{Na}$ Empresa Smith \& Pedro existem 80 peças $(97,6 \%)$ que não referem qualquer ilícito, sendo que existem 38 peças (46,3\%) associadas a "suborno" e 29 peças $(35,4 \%)$ a "corrupção". As Empresas Internacionais estão igualmente relacionadas com os crimes de "suborno" (14 peças, 42,4\%) e "corrupção" (13 peças, 39,4\%). Este último ilícito é referido a propósito do Escritório de Advogados Vasco Vieira de Almeida \& Associados (6, 46,2\%, peças, sendo que existem 12, 92,3\% peças em que não há menção a nenhum ilícito, bem como à Empresa ISA-Investimentos Imobiliários, LDA (7, 70\% e 9, 90\%, sem referência a ilícitos) e ao Ateliê Arquiteto Eduardo Capinha Lopes (6, 75\% peças em que 7 não referem ilícitos).

No Face Oculta (Gráfico 6) ) $^{22}$ no total de 342 peças, apenas são nomeadas três instituições privadas, o BCP (61 peças, 7\%), a 02 (30 peças, 3,5\%) e a SCI (8 peças, $0,5 \%$ ), estas últimas pertencentes ao grupo empresarial de Manuel Godinho, acusado de ser o corruptor. Nas duas primeiras empresas o "tráfico de influências" e a "corrupção" são os ilícitos mais nomeados. 0 "tráfico de influências" recolhe, respectivamente 25 peças, 23,6\% no BCP e $5(9,8 \%)$ à 02 . A "corrupção" regista 13 peças $(12,3 \%)$ associadas ao BCP e 6 peças $(11,8 \%)$ à 02 . 0 "crime contra a economia" está igualmente associado à empresa 02 num total de 3 peças $(5,9 \%)$.

20 Anexo l, final do artigo, p. 60.

21 Anexo I, final do artigo, p. 60.

22 Anexo l, final do artigo, p. 60. 
A interpretação destes outputs mostra que as empresas privadas não estão na maior parte das notícias agregadas a ilícitos. Nos casos em que essa situação ocorre, as empresas mais nomeadas estão em sintonia com a temática de cada caso. No caso Freeporta proeminência é do escritório de intermediação imobiliária, Smith \& Pedro, que representou empresas internacionais interessadas no negócio de construção do outlet. Salientamos também a nomeação do escritório de Advogados Vasco Vieira de Almeida \& Associados implicados no "possível" encobrimento de atos de corrupção. No caso Face Oculta a instituição mais referida é o Banco Comercial Português (BCP) onde exercia funções o principal arguido, o ex-ministro do Partido Socialista (PS), Armando Vara. A nomeação do BCP está associada ao ilícito tráfico de influências, não só porque Armando Vara foi nomeado em representação do Governo, mas porque é estabelecida a sua relação de proximidade com o Primeiro-ministro de então, José Sócrates, bem como com os outros atores implicados no processo. A empresa 02 , pertencente ao empresário corruptor, surge com menos visibilidade, igualmente associada à corrupção e ao tráfico de influências. Os indicadores levantados apontam para que 0 ator político constituído arguido determine a qualidade da instituição privada, no caso do BCP. 0 corruptor, o empresário Manuel Godinho, tal como já fora observado na análise dos indicadores relativos aos atores, e as suas empresas, por terem pouca visibilidade, parecem não determinar a perceção da qualidade das instituições privadas.

Assinalamos qua a análise dos dois casos sublinha, antes de mais, o papel das rotinas televisivas jornalísticas na cobertura dos fenómenos de corrupção política. A natureza do meio e do "fazer" televisão, a necessidade de preencher tempo com imagem e desta conter referentes — pessoas, cenários, "falas" — facilmente identificáveis, estão presentes no elevado número de "declarações", bem como na proeminência dada às notícias sobre "investigações, buscas e interrogatórios" registadas nos casos. Por outro lado, observamos que as "declarações" estão preferencialmente associadas ao Primeiro-ministro José Sócrates, tanto no caso Freeport em que é o principal implicado, como no caso Face Oculta onde surge como "amigo" do principal político arguido, o ex-ministro Armando Vara. Salientamos também que, em sentido contrário, as notícias e os tempos atribuídos aos corruptores são muito diminutos, ao que acresce não serem, na generalidade, figuras públicas. No caso Freeport, os corruptores são empresas internacionais intermediadas por um escritório nacional e, no caso Face Oculta, um obscuro empresário nacional da sucata. Em ambos os casos estes atores individuais ou coletivos têm menor expressão que os atores políticos. Protagonismo tem, ainda, 0 Ministério Público, através das declarações do Procurador da Justiça e dos Procuradores Gerais adjuntos, o que é demonstrativo, também, das rotinas de um jornalismo de "secretária", muito centrado em fontes oficiais acessíveis a um " telefonema".

\section{BREVES CONCLUsões}

Procurámos demonstrar a partir da exposição teórica que, nestes últimos anos, a natureza da democracia alterou-se, principalmente na Europa do Sul. Os indicadores desta mudança são, não só sociais (transformações dos direitos sociais e trabaIhistas adquiridos na pós-segunda guerra mundial), como também políticos (menor participação nas eleições e aumento da desconfiança face aos sistemas políticos e partidários). A desregulamentação dos media nos finais da década de oitenta e início da década de noventa, a entrada de capitais externos ao campo mediático e 
a integração em grupos com áreas e interesses diversificados modificaram profundamente o funcionamento dos media na Europa, até então considerados um serviço ao público, independentemente de serem efetuados por empresas públicas ou privadas. Paulatinamente, a atividade jornalística foi-se subordinando às audiências, aos anunciantes e aos grandes interesses do capital, promovendo discursos "conformistas" e adquirindo caraterísticas de inforentretenimento. Com a crise de 2008, acentuam-se os indícios de restrição à liberdade de imprensa e de expressão (The Economist. 2013), a partir de mecanismo de autocensura resultantes da precarização dos jornalistas e da redução de postos de trabalho. A estes factos acrescem as pressões externas de grupos económicos e financeiros, muitas vezes acionistas dos meios de comunicação, interessados em inculcar nos cidadãos o pensamento dominante da inevitabilidade de uma única solução política, económica e financeira.

A cobertura jornalística da corrupção política surge nos noticiários com grande visibilidade nos anos de crise, acompanhando a perceção que muitos cidadãos têm deste fenómeno. A denúncia e a desocultação deste ilícito constitui um serviço prestado à democracia mas, por outro lado, os procedimentos de agendamento, que atribuem maior proeminência, destaque ou relevância a determinados temas ou atores políticos, facilitam a interiorização pela opinião pública de uma perceção de "saliência" relativamente à qualidade dos representantes "corruptos" da democracia. Por conseguinte, observamos uma crescente desconfiança face à democracia e à capacidade dos políticos representarem o interesse coletivo dos cidadãos.

Ao assumir os padrões ou síndromes de corrupção identificados por Jonhston (2005), pretendemos compreender, numa perspetiva da globalização neoliberal inevitável, como a cobertura jornalística do fenómeno carateriza atores políticos, judiciais e empresariais, bem como são apresentadas as instituições públicas e privadas. 0 modelo sublinha que os períodos de "transição" entre modelos são favoráveis ao aumento da corrupção, nomeadamente política. No caso português, a democracia recente e a assunção de um modelo liberal, principalmente desde o início do milénio, parece constituir um caldo para a emergência destes fenómenos. Os indicadores que apresentamos, nomeadamente aqueles que demonstram a proeminência atribuída às figuras políticas ou da magistratura na televisão, contribuem para uma perceção descredibilizada da política e das instituições democráticas. Esta perceção construída a partir da televisão parece advir, não propriamente dos conteúdos informativos veiculados, ou das investigações aprofundadas sobre a temática, mas sim da repetição de sound-bytes e de imagesbytes, vinculando o campo semântico da corrupção ao campo da política e da justiça.

Ainda com base nos outputs e na tipologia descrita por Jonhston (2005), parecenos possível situar a corrupção em Portugal numa fase de transição entre "Cartéis de Elite" e "Influência de Mercados" onde o padrão de democracia se encontra em fase de adaptação a um "mercado" liberal e globalizado. Neste sentido, verificamos na cobertura jornalística elementos de reformulação/desacreditação de atores políticos e instituições públicas, assim como assinalamos o papel restrito da participação cívica, praticamente sem voz na televisão, e o "apagamento" dos atores não políticos, tais como instituições, gestores, advogados, etc.

Os resultados apontam, ainda, para o papel das rotinas jornalísticas e 0 valor dos critérios notícia na televisão, tais como obter "declarações" (testemunhos) de figuras publicamente reconhecidas, assim como para a relevância dada ao "conflito" entre ato- 
res, a partir das "declarações". Por outro lado, a análise indicia que a perceção tende a estar mais vinculada à image-byte e ao som-byte do que, propriamente, aos conteúdos da notícia. Neste sentido, a saliência (priming) conferida a um determinado político está sempre associada a temas e atributos específicos, e são estes elementos que contribuem para a construção da perceção sobre determinado ator político. A enunciação desses temas e atributos leva à identificação, pelos cidadãos, desse político; a nomeação na televisão desse político carrega, por sua vez, o tema e o conjunto de atributos que lhe estão associados. Na análise da televisão das notícias políticas, ressaltamos a importância da perceção criada a partir de elementos presentes nas imagens, as quais permitem ao espetador, cidadão e eleitor, formar a sua opinião sobre a credibilidade, confiança e responsabilidade das instituições e atores. Outros fatores, tais como os não-verbais (gesto, postura, vestuário, atitudes, etc.) e os recursos técnicos de edição (cortes, zooms, seleção de ângulos, som acoplado, etc.) (Grabe, 2009) contribuem para acentuar a perceção "pouco favorável" sobre instituições e figuras públicas.

\section{Bibliografia}

Blankenburg, E. (2002). From Political Clientelism to Outrighy Corruption - The rise of the

Scandal Industry. In: Kotkin, S. \& A. Sajó, A. (eds.). Political Corruption in transition: a sceptic's handbook (pp.149-165). Budapeste: CEU Press, Central European University Press. Cunha, I. F. (2012). A cobertura televisiva de Partidos, Candidatos e Temas nas Legislativas.

In: Figueiras, R. (org.). Os Media e as Eleições: Europeias, Legislativas e Autárquicas (pp. 95-131). Lisboa: Universidade Católica Editora.

Di Tella, R. e Franceschelli, I. (2011). Government Advertising and Media Coverage of Corruption Scandals. American Economic Journal: Applied Economics 3 (October):119-151. Economakis, G., Rizopoulos, Y., Sergakis, D. (2010). Patters of Corruption. Journal of Economics and Business. vol. 13 (2): 11-31.

Grabe, M. E. (2009). Image bite politics. News and the visual framing of elections. Oxford: Oxford University Press.

Johnston, M. (2005). Syndromes of Corruption: Wealth, Power and Democracy. Cambridge: Cambridge University Press.

Maia, A.J. (2008). Corrupção: Realidade e Percepção - o Papel da Imprensa,.Tese de Mestrado. Lisboa: Instituto Superior de Ciências Sociais.

Morgado, M. J. e Vegar, J. (2003). Fraude e corrupção em Portugal: o inimigo sem rosto. Lisboa: Publicações D. Quixote.

Roca, T. \& Alidedeoglu-Buchner, E. (2010). Corruption Perceptions: The Trape of Democratization, a Panel Data Analysis. Social Science Research Network. (http://papers.ssrn. com/sol3/papers.cfm?abstract_id=1725434) (acedido 09/2004)

Sampaio, G. (2013). Os privilegiados. Lisboa: A Esfera dos Livros.

Sampaio, G. (2014). Os facilitadores. Lisboa: A Esfera dos Livros.

Schudson, M. (2004). Notes on Scandal and the Watergate Legacy. American Behavioral Scientist 47: 1231-1238.

Streeck, W. (2013). Tempo comprado: a crise adiada do capitalismo democrático: Lições Adorno em Frankfurt, 2012. Coimbra: Conjuntura Actual Editora. 
The Economist (2013). Democracy index 2012: A report from The Economist Intelligence Unit. (https://portoncv.gov.cv/dhub/porton.por_global.open_file?p_doc_id=1034) (acedido 09/2014) Vala, J. \& Monteiro, M. B. (1996). Psicologia Social. Lisboa: Fundação Gulbenkian.

\section{Anexo I.}

Gráfico 1. Caso Freeport. Temas e Atores principais (\%)

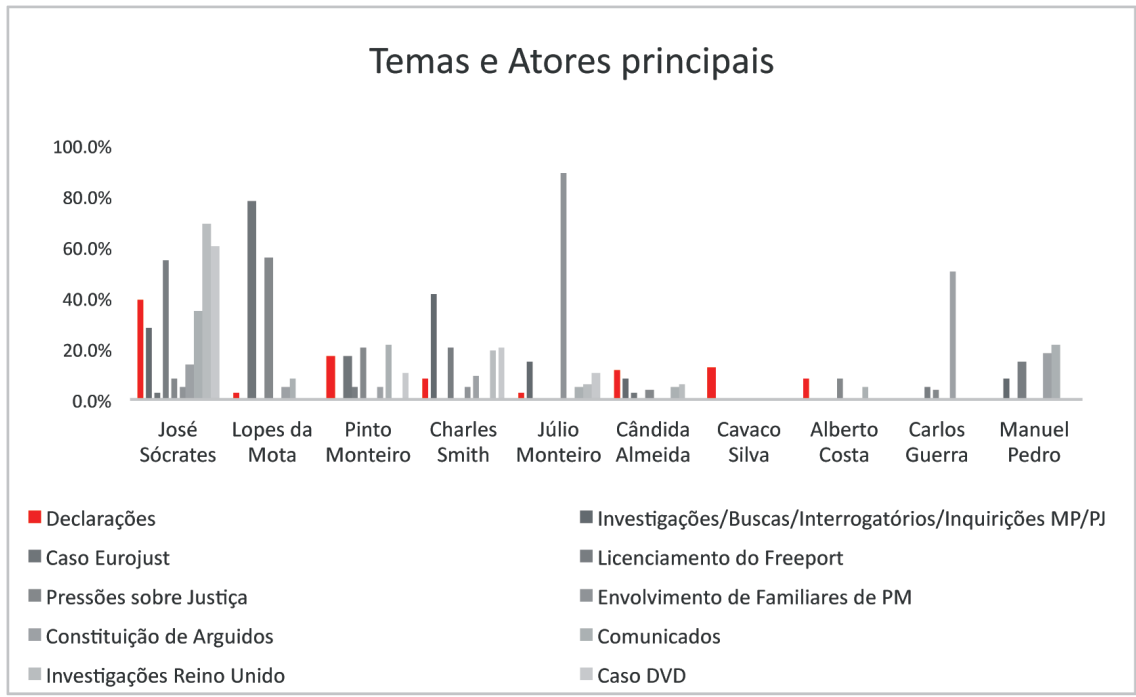

$\mathrm{N}:{ }^{0}=689$ (Número total de peças)

Fonte: Dados da empresa Marktest/Mediamonitor

Gráfico 2. Caso Face Oculta: Temas e Atores principais (\%)

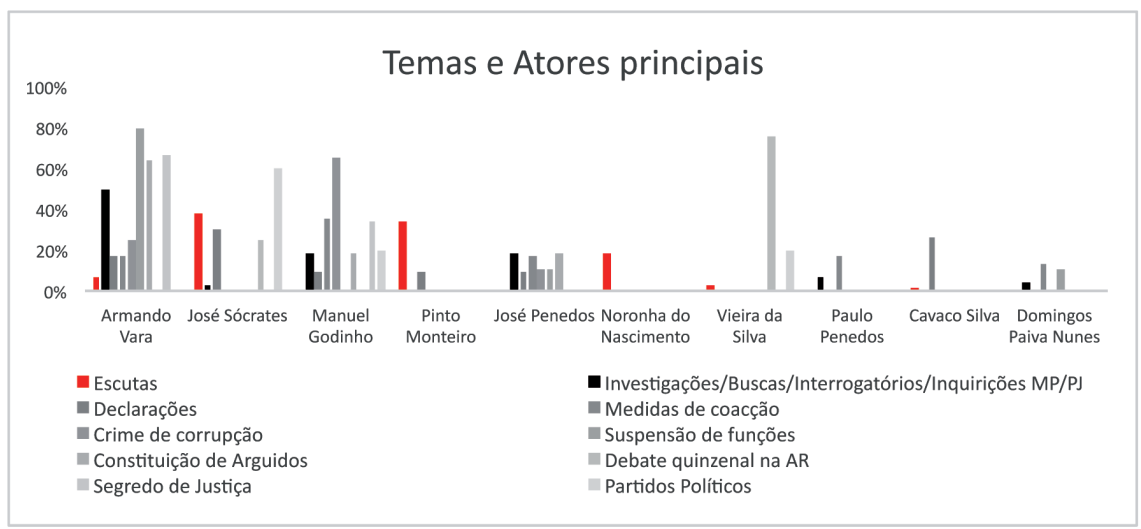

$\mathrm{N}:=342$ (Número total de peças)

Fonte: Dados da empresa Marktest/Mediamonitor 
Gráfico 3. Caso Freeport: Instituições Públicas e llícitos (\%)

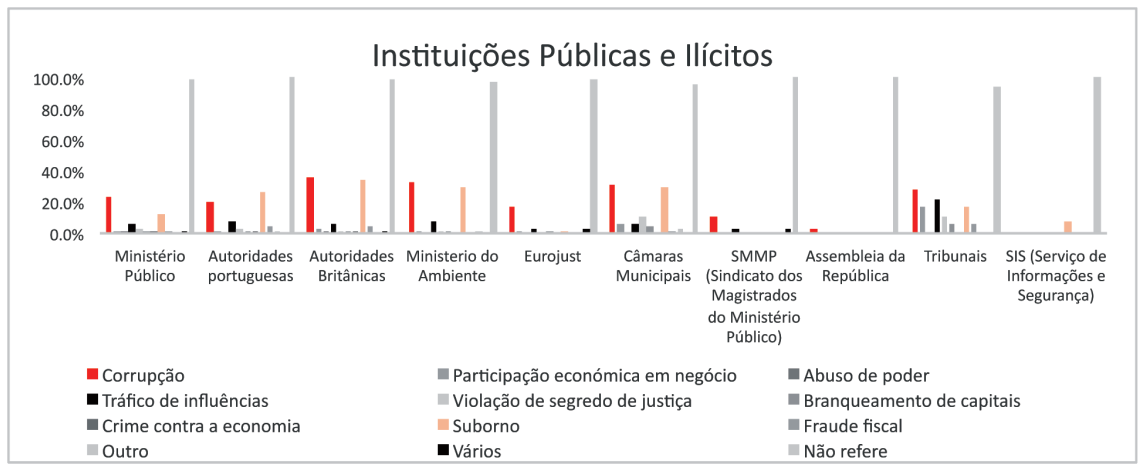

$\mathrm{N}:=342$ (Número total de peças)

Gráfico 4. Caso Face Oculta: Instituições Públicas e llícitos (\%)

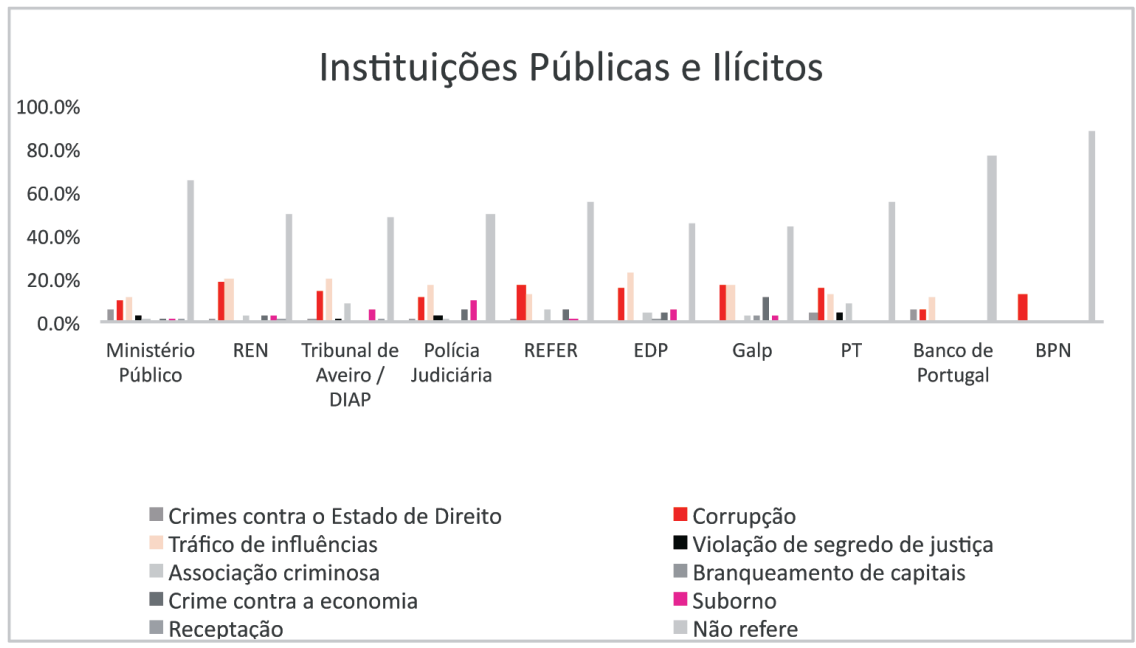

$\mathrm{N}^{: 0}=342$ (Número total de peças) 


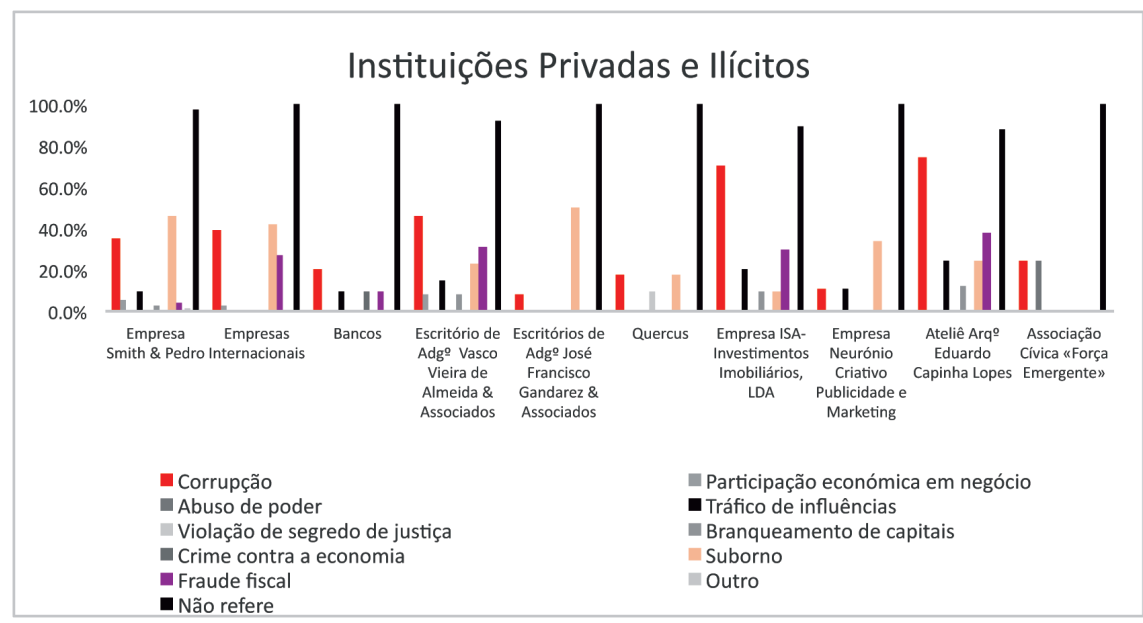

$\mathrm{N}:=342$ (Número total de peças)

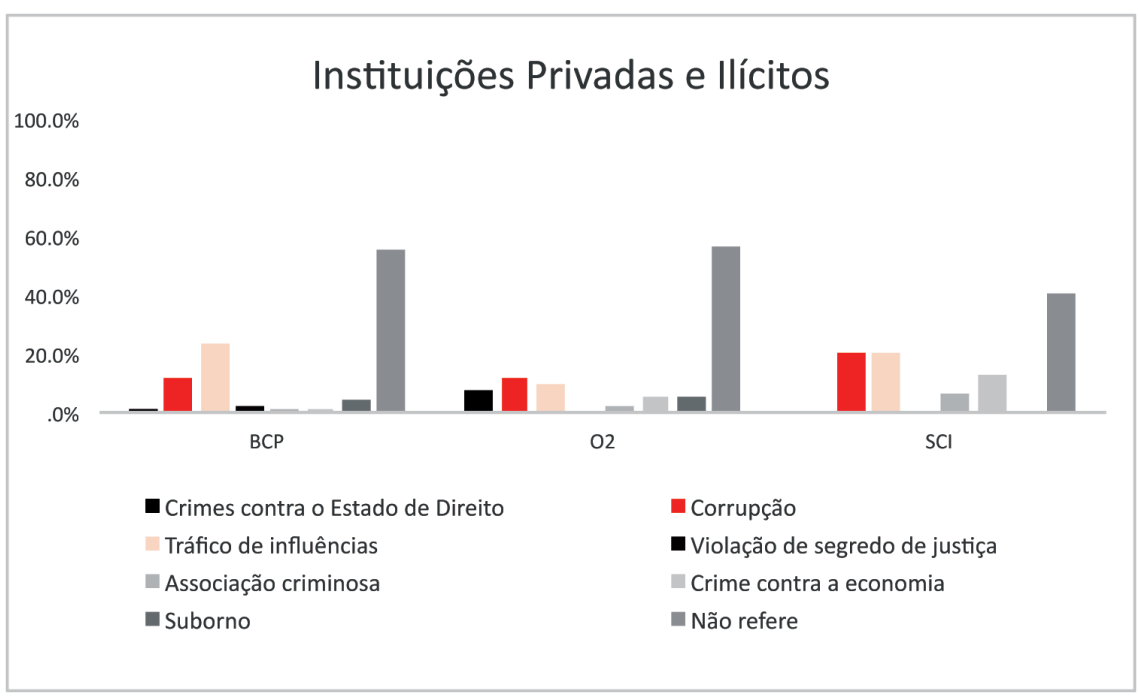

$\mathrm{N}:{ }^{\circ}=342$ (Número total de peças)

AneXo II.

Caso Freeport: 0 “Caso Freeport reporta-se ao ano de 1999, quando uma multinacional irlandesa designada McKinney, do ramo da promoção imobiliária, apresenta no Instituto da Conservação da Natureza (ICN) um pedido de informação acerca da possibilidade de reconversão da antiga fábrica de pneus Firestone num complexo lúdico-comercial, a que chamaria de "Designer Village". O local estava dentro da Zona de Protecção Especial (ZPE) da Reserva Natural do Estuário do Tejo e, para se concretizar o empreendimento, era necessário alterar os limites legalmente defi- 
nidos dessa ZPE. Em 2000 é contratada a empresa de consultadoria Smith\&Pedro para acompanhar todas as burocracias com vista à legalização do empreendimento em Portugal. Em fevereiro, o advogado Manuel Pedro, sócio da consultora, foi nomeado assessor principal para aquela Reserva Natural, juntamente com um outro ambientalista e professor universitário. Um estudo de impacte ambiental, contendo as recomendações anteriores, é realizado. A 10 de junho de 2000, inicia-se o processo de avaliação, proposto pela McKinney e executado pela PlaniPlano. Em outubro do mesmo ano, é emitida uma Declaração de Desconformidade, na qual é expresso que o Estudo não permitia a avaliação dos eventuais impactes do projeto. Como tal, o projeto seria cancelado. A McKinney perde o interesse no investimento e vende 0 terreno à Freeport Leisure(2001), uma empresa especializada em outlets. 0 então secretário de Estado do Ordenamento do Território e da Conservação da Natureza pede ao ICN que reavalie os limites da ZPE do Estuário do Tejo, pois entende que não se deveria aplicar à área em questão o estatuto de ZPE. A Freeport Leisure apresenta um novo Estudo de Impacte Ambiental elaborado pela Mitchell MCFarlane \& Partner. Surgem movimentações na embaixada inglesa com vista a pressionar a aprovação do projeto junto do então Secretário de Estado do Ambiente, José Sócrates. É neste período que surgem as acusações de que a Smith\&Pedro terá solicitado 4 milhões de libras para desbloquear o licenciamento do Freeport. Este dinheiro seria para os próprios, que foram constituídos arguidos e ilibados, em julho de 2012, ou para o mencionado ministro do PS, eleito primeiro-ministro em 2005. 0 caso Freeport foi despoletado nesse ano através de uma carta anónima, posteriormente identificada como redigida por um militante do CDS, acusando o então ministro do Ambiente de ter recebido "luvas" a troco da autorização para construção de um outlet numa zona dita protegida, situada no estuário do rio Tejo, financiado pelo consórcio britânico Freeport. A polícia investiga as denúncias e surgem inúmeras referências às luvas que José Sócrates, ou familiares, terão recebido. A polícia inglesa, através do Serious Fraud Office, investiga a empresa Carlyle, que se tornou dona do empreendimento em 2007. 0 Eurojust, organização de Justiça que coordena atividades neste âmbito na Europa, é coordenado por um advogado e anterior colega do primeiro-ministro, e recusa-se a dar seguimento ao processo. 0 coordenador é afastado. Durante o julgamento do processo foram constituídos arguidos sete cidadãos e, posteriormente, todos ilibados. 0 primeiro-ministro nunca viria a ser constituído arguido nem a ser ouvido como testemunha.

Caso Face Oculta: foi noticiado em 2009 no decurso de uma investigação que a Polícia Judiciária de Aveiro desencadeou em vários pontos do país. As diligências visaram apurar alegados crimes económicos (lavagem de dinheiro, corrupção política e evasão fiscal) de um grupo empresarial, cujo responsável teria montado uma rede envolvendo antigos titulares de cargos governativos, funcionários autárquicos e de empresas públicas, e militares, com o objetivo de obter benefícios para os negócios das suas empresas na área da seleção, recolha e tratamento de resíduos. 0 caso conta com 36 arguidos (34 pessoas e duas empresas), entre eles destacados membros políticos do PS e altos funcionários de empresas públicas. 0 Ministério Público acusa o dono das empresas de criar uma teia de influências que permitiria obter informação privilegiada e, por conseguinte, vantagens para o seu grupo em- 
presarial. Nesta teia encontram-se as maiores empresas públicas portuguesas (REN, REFER, CP e EDP) e, também, grandes empresas privadas. 0 processo ganhou grande visibilidade mediática quando foi denunciada a existência de escutas telefónicas e mensagens escritas trocadas entre o primeiro-ministro José Sócrates e o principal político constituído arguido (Armando Vara). 0 caso foi julgado e dois dos arguidos, Armando Vara e José Penedos condenados a penas de prisão que recorreram. 